\title{
Un nuevo reto: la sección Información: PATRIMONIO HISTÓRICO ANDALUZ
}

\section{Carmen Ladrón de Guevara}

Dpto. de Documentación del IAPH

\begin{abstract}
Una presentación de una nueva sección editorial para una revista especializada tiende siempre a entenderse como una declaración de intenciones. Si intención es la vocación de provocar una mejora, subsanar una carencia, inducir al avance, la reflexión es expresa. Si intención denota una duda, una incertidumbre, por la propia idiosincrasia de lo que se desea, quizá la presentación sea necesaria.
\end{abstract}

Un título que introduzca al lector, "Información: Patrimonio Histórico Andaluz", una necesidad que ilustre el panorama: ser plataforma de información del patrimonio histórico andaluz, con una estructura mixta y complementaria para acceder a la divulgación y análisis del patrimonio histórico junto a los datos del mismo.

Lo que define este empeño es la capacidad de mostrar resultados del trabajo del Centro de Documentación, acompañados de análisis completos de investigadores que centren el contexto. Líneas programáticas que irán dando sentido a estas determinaciones. Porque el proyecto que ahora inicia es un lugar de interpretación y de conocimiento, si uno puede andar sin lo otro, y su mismo caminar será el que alcance un horizonte. Por ello la incertidumbre. No es indecisión en el planteamiento, es el reconocimiento de la dificultad de saber qué nos depararán los trabajos y su repercusión en el ámbito social del boletín.

Y es que la llamada está hecha. Se va a invitar a diferentes personas que por su trabajo o capacidad de análisis vayan dando sentido, completando un corpus de conocimiento que no existía explícito en las publicaciones actuales. No hay más que echar una ojeada a las revistas patrimoniales o de intervenciones profesionales para darnos cuenta del hueco que ahora pretendemos cubrir. De las monografías o dossieres temáticos, a las obligadas reseñas historiográficas para comprender las intervenciones, no hay paso intermedio. Sería necesario, por tanto, sectorializar el análisis del patrimonio con arreglo a variables diversas, tales como: bienes singulares, delimitaciones territoriales (parques naturales, comarcas, centros urbanos, provincias, municipios, etc.), autores y sus obras en Andalucía, periodos históricos, determinadas tipologías, bienes integrados en rutas culturales...
El método de trabajo que se sigue en algunos casos dentro del Centro de Documentación recurre a la estrategia de la cualificación de datos mediante líneas temáticas. Es una organización que permite ir realizando estudios paralelos a la consecución de la información. Tras varios años de experiencia, se puede "navegar" por las bases de datos para verdaderamente extraer de ellas un potencial de análisis que ponga en valor nuestro patrimonio. Los cruces de información deben empezar a dar frutos como aspectos de investigación nuevos, aporte de datos para otras en marcha, mayor divulgación que redunde en el entendimiento general de lo que significa el pasado y en particular para fundar una labor de intervención acorde con el presente.

Como colaboradores se pretende invitar a investigadores o profesionales que estén especializados en los distintos sectores, aunque se potenciaría una lectura integrada acerca de un mismo ámbito temático en un medio dinámico como es la periodicidad de la revista.

En cuanto a la estructura argumental de los artículos trataremos de seguir un modelo que se irá perfilando con el tiempo: Introducción, Análisis de las características generales, Valoración del interés y el Estado actual

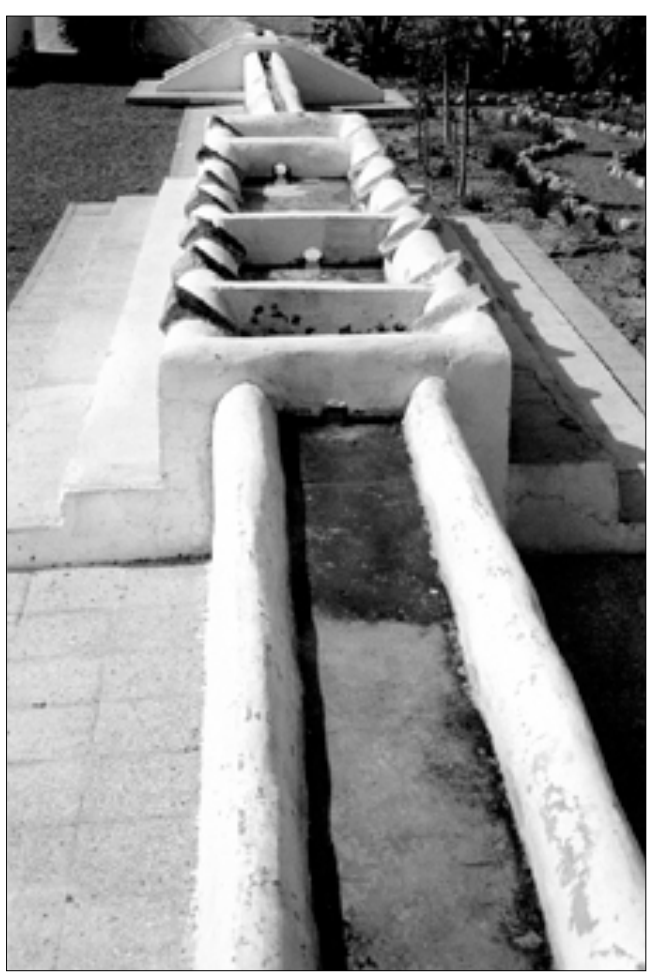




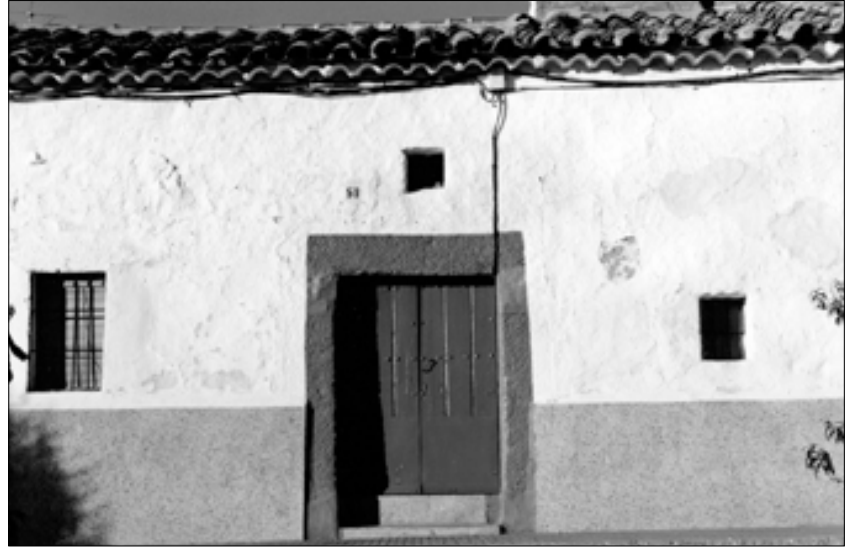

del patrimonio recogido, Propuestas de acciones y Selección de datos con documentación gráfica ilustrativa del contenido.

Verdaderamente, la puesta en valor del "dato" es lo que se persigue aquí. Existe un vocablo explicitado en el léxico que adjudica un concepto apto para lo que queremos transmitir:

"Antecedente necesario para llegar al conocimiento exacto de una cosa o para deducir las consecuencias legítimas de un hecho".

Quizá el enganche más recurrente para este aforismo sea nombrar algo del conocimiento de nosotros mismos, puesto que el pensamiento "patrimonial" no es más que saber de uno mismo, con unos fines, probablemente aún difusos, pero de ineludible presencia. Si el mundo es "la totalidad de los hechos, no de las cosas", en frase de Wittgenstein, el diccionario aporta un significado acorde con las intenciones de la nueva sección y es un síntoma más de la búsqueda de un estar contemporáneo.

Dato, referido en un contexto -no podría ser de otra manera-que se exprese como presencia, no alude

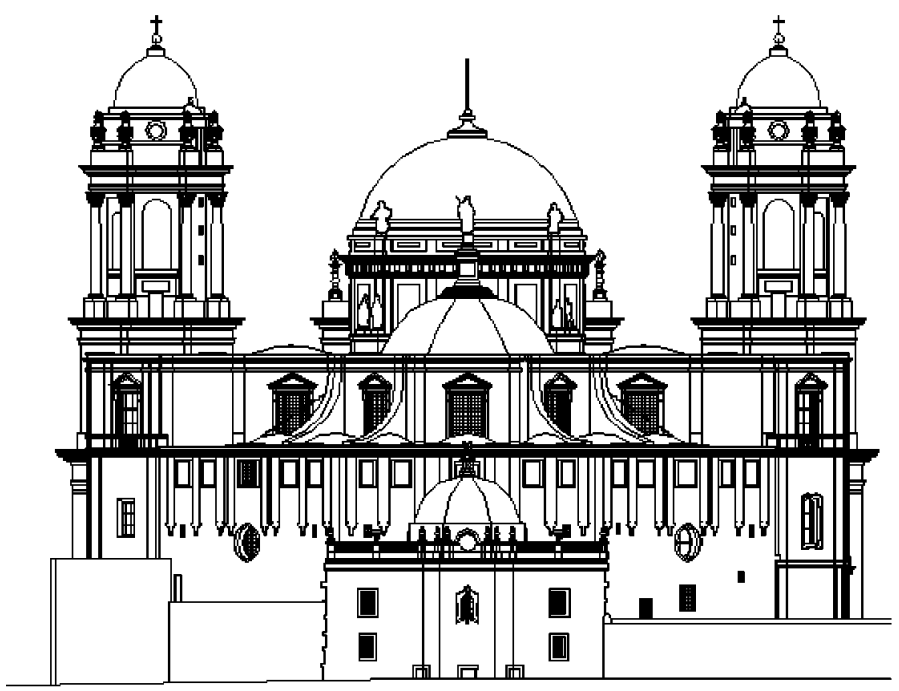

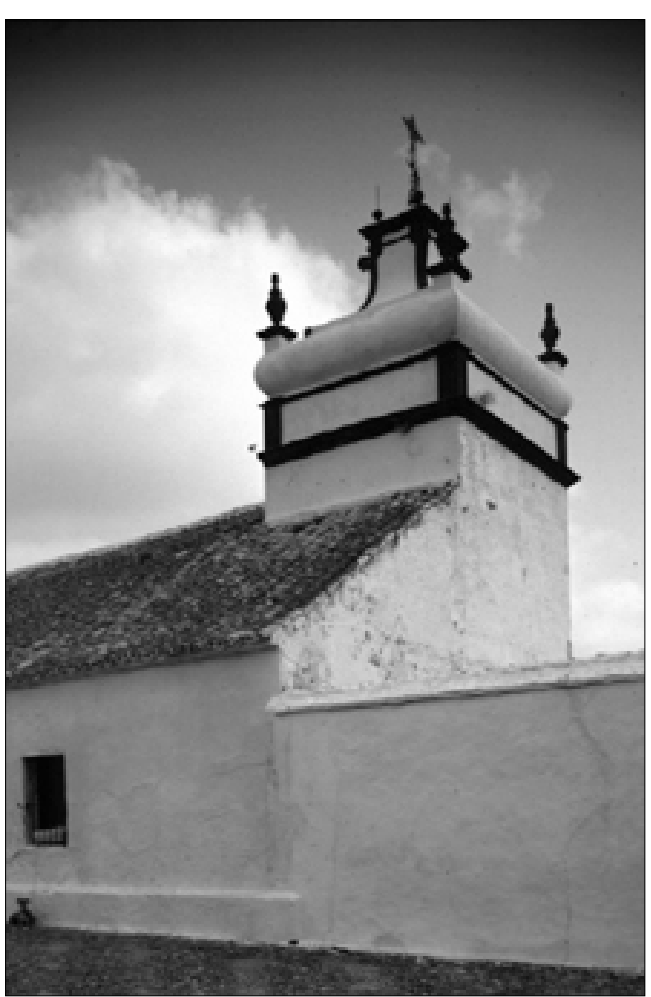

tanto a ser (establecido en presencia) como al impersonal "hay" o "se da". Se da el ser o se da el tiempo, son claves de pensamiento usadas por Ortega o Heidegger junto a "dato" o "don" con un sabor más o menos mítico, representando envío, misión y destino. Asociaciones de conceptos para un actuar, y para indicar la variabilidad semántica. Hay que analizar sabiendo que se "da" el contexto al hacerlo. La información no existe sin más, es todo un proceso de construcción sistemática.

Puede que estas palabras sean tomadas como analogías de cierta inmediatez entre pensamientos complejos y realidades prácticas, pero nos preguntamos si no es, por contra, al hablar de ser y tiempo, un hablar propicio consciente de nuestra misma caducidad. Un hablar que entiende su pasado desde el presente, que lo ve evolucionar y que lo sabe valorar.

Lo que antecede al análisis y el análisis. Datos y pensamientos. Damos el contenido y el contexto, el ser y el tiempo.

Desde 1992, inicio de la andadura de este boletín, hasta hoy, sucesivos cambios han perfilado lo que es ahora PH. Y en adelante, sucesivos cambios harán de $\mathrm{PH}$ una revista siempre en busca de conocimiento, de documentación, de reflexión, en permanente transformación.

Creemos que como apuesta es importante y supone para el Centro de Documentación del Instituto Andaluz de Patrimonio Histórico un reto más en una labor que quiere aportar significados enriquecedores al trabajo que realiza. 